\title{
A STATE ENTROPY MODEL INTEGRATED WITH BSC AND ANP FOR SUPPLIER EVALUATION AND SELECTION
}

\author{
Pan, R. ${ }^{* *}$; Zhang, W. ${ }^{*}$; Yang, S. ${ }^{*} \&$ Xiao, Y. ${ }^{* *}$ \\ *School of Management of Hefei University of Technology, Hefei 230009, China \\ ${ }^{* *}$ School of Foreign Studies, Hefei University of Technology, Hefei 230009, Anhui, China \\ E-Mail: hfutpry@126.com ( ${ }^{\circ}$ Corresponding author)
}

\begin{abstract}
This paper proposed a new method for supplier evaluation and selection after analysing the supplier state evolutionary process according to the entropy change process in the thermodynamics. In order to verify the feasibility of the new proposed method, we applied it to a maintenance, repair and overhaul/operation enterprise. Besides, we analysed the characteristics and problems of the maintenance, repair and overhaul/operation industry firstly, and then established an index system and calculated weights by balanced scorecard and analytic network process respectively. The results calculated by the proposed method are proved to be in accordance with the reality.

(Received, processed and accepted by the Chinese Representative Office.)
\end{abstract}

Key Words: State Entropy, Supplier Evaluation, Analytic Network Process, Balanced Scorecard

\section{INTRODUCTION}

As the researches and applications of supply chain management deepening unceasingly, the importance of supplier evaluation and selection has been gaining more and more recognition and attention from both enterprises and scholars. And a great many studies have been drawn into this field. Because the factor of influencing supplier performance is always not unitary [1] and experts have different standpoints or surroundings when they make decisions, etc., the supplier evaluation and selection has been treated as multiple criteria decision making (MCDM) [2-4].

The quantification of the indexes in supplier evaluation always cannot be fully carried out so that there emerges some research directions such as qualitative analysis and quantitative evaluation as well as how to quantify the qualitative indexes in quantitative evaluation, etc. [5-9]. Anyway, supplier evaluation needs to determine the corresponding indexes firstly. And the stand or fall of the selected indexes will seriously affect rationality of the follow-up evaluation results. So many scholars lucubrate on this problem. The earliest study that also has the greatest impact was made by Dickson [10] in 1966. In his study, Dickson validated 23 criteria for assessing vendor's performance based on the responses of 170 purchasing agents and managers. According to the results, Dickson regarded the Quality as an Extremely Important criterion in supplier selection, and the Reciprocal Arrangement was categorized as a Slight Importance criterion. Weber et al. [11] summarized the articles referring to supplier selection since 1966, and found the top three criteria for evaluating supplier is Price, Delivery and Quality. Yahya and Kingsman [12] compared the indexes at all level of the index system by analytic hierarchy process (AHP), and obtained the orders of importance of the indexes in the first level is Delivery, Quality, Facility, Technical Capability, Financial, Management, Discipline, and Responsiveness. The corresponding researches on index selection are also in many other articles [13-15].

Similarly to the studies of index selection and evaluation, a great number of methods also have been applied to the solution of the problems in order to be able to select suppliers in demand for the enterprise from plenty of potential suppliers. These methods include 
mathematical programming, artificial intelligence and some other multi-criteria decision making methods. Saen [16] proposed a data envelopment analysis (DEA) methodology for supplier selection that considered both undesirable outputs and imprecise data simultaneously. $\mathrm{Wu}$ [17] applied DEA in the module 1 of two modules of the model for the supplier classification based on resulting efficiency scores. Saen [18] proposed an assurance regionimprecise data envelopment analysis (AR-IDEA) model for supplier selection in the presence of both weight restrictions and imprecise data. Wang et al. [19] established linear programming models for generating interval priority weights from additive consistent or inconsistent interval fuzzy preference relations. Amid et al. [20] developed a fuzzy multiobjective linear model to overcome the vagueness of the information in the supplier selection decision-making. Razmi et al. [21] presented a two-stage integrated framework for supplier selection and formulated an integer programming with fuzzy objectives and constraints in the second stage. Guneri et al. [22] presented an integrated fuzzy and linear programming approach for the problem of the supplier selection that included both tangible and intangible factors. Kokangul and Susuz [23] constructed an integrated model of AHP and non-linear integer and multi-objective programming to maximize the total value of purchase, or minimize the total cost of purchase, or both simultaneously. Razmi and Rafiei [24] applied analytic network process (ANP) to qualify suppliers and filter suitable candidates among the available ones. Li et al. [25] applied an integrated approach of rough set and grey relational analysis to a real case to select the most suitable supplier. Che and Wang [26] proposed a genetic algorithm to solve the constructed optimal mathematical model that considered the limited production capacity of suppliers. Kubat and Yuce [27] proposed a general framework that combined analytic hierarchy process, fuzzy analytic hierarchy process and genetic algorithm to determine the best set of suppliers. Liao and Rittscher [28] developed a multiobjective programming model to determine several objectives that included supplier selection and obtained the results by the designed genetic algorithm. Chen et al. [29] used back propagation neutral networks to calculate the weight of the indexes for the complex and unstructured supplier selection decision and selected the best supplier by grey correlation analysis. Lee and Ou-Yang [30] developed an artificial neural network-based predictive model to improve the efficiency in the supplier selection process. Wen [31] established an assessment model by integrating analytic hierarchy process and knowledge management effectiveness for improving the measurement of knowledge management effectiveness in Taiwanese high-tech enterprises. Yucenur et al. [32] made a comparison between fuzzy AHP and fuzzy ANP that applied to supplier selection in global supply chains. Chamodrakas et al. [33] integrated rating scale AHP and fuzzy preference programming in order to enable effective supplier selection processes in electronic marketplaces. Tang and Chang [34] utilized goal programming and fuzzy AHP to help decision-makers choosing a suitable alternative within the companies' goal, constraints and strategies. Shemshadi et al. [35] extended the 'Vlsekriterijumska Optimizacija I Kompromisno Resenje' (VIKOR) method with a mechanism to extract and deploy objective weights based on Shannon entropy concept and proposed a numerical supplier selection example to illustrate an application of the proposed method. Opricovic and Tzeng [36] gave a comparative analysis between VIKOR and TOPSIS (i.e. Technique for Order Preference by Similarity to Ideal Solution) that were both used as MCDM methods and based on an aggregating function representing "closeness to the ideal". Noor-E-Alam et al. [37] proposed two algorithms in order to handle the difficulty in the conflict aggregation process of multi-expert multi-criteria decision making.

As many papers mentioned, the process of supplier evaluation is full filled with tangible and intangible information. How to aggregate these complex and unstructured information reasonably has been a research hotspot in this field. The main purpose of this paper is to mimic the supplier state evolutionary process based on the concept of entropy in 
thermodynamics to deduce a reasonable supplier information integration method for supplier selection decision making. The rest of this paper is organized as follows: In Section 2, we make a brief review to the contents of entropy, balanced scorecard (BSC) and ANP, and the reasons of choosing these methods in this paper are also illustrated respectively in each subsection. In Section 3, we analyse the similarity between the supplier state evolutionary process and the entropy change process in thermodynamics, and elaborate the deduction process and the calculation steps of the method as well. In Section 4, we first give a description of the characteristics and problems in the maintenance, repair and overhaul/operation (hereinafter referred to as MRO) enterprises. Then, we establish a corresponding index system by BSC according to the characteristics, and calculate the weights of the indexes which have dependencies relationships by ANP. Finally, the state entropy calculation is carried out by using the weights we gained and the suppliers' state information. In Section 5, the conclusions and future research directions are discussed.

\section{PRELIMINARIES}

\subsection{Entropy}

As we all know, the second law of thermodynamics is solving the problems of directionality and irreversibility in the transmission and conversion process of energy. Although the expressions of the second law of thermodynamics between Clausius and Kelvin are different, the essence of their expressions is the same, that is, "the process occurred in the isolated system always makes the entropy value of the entire system increasing". This is also the meaning of the inequality $\Delta S \geq 0$ which Clausius proposed in 1865, and named as "the principle of entropy increase". The more general mathematical inequality can be expressed as:

$$
d S \geq \frac{d Q}{T}
$$

In inequality (1), $d S$ is the infinitesimal element of entropy and $d Q$ is the infinitesimal element of heat that absorbed from the environment by the system at absolute temperature $T$. The symbol " =" is corresponding to the reversible process in the isolated system, and the symbol " $>$ " is corresponding to the irreversible process in the isolated system.

From inequality (1), we can conclude that the entropy described by Clausius is just the research result of the appearances in the system, and the microscopic nature of entropy isn't explored. So the Austrian physicist Boltzmann studied the physical meaning of entropy by statistical methods from the point of view of the kinetic theory, and proposed a statistic formula of entropy in 1877 shown as:

$$
S=k \ln \Omega
$$

In eq. (2), $k=1.3806505 \times 10^{23} \mathrm{~J} / \mathrm{K}$, which is called the Boltzmann constant; $\Omega$ is the number of microscopic state of the system. Eq. (2) reveals the general meaning of entropy, that is, entropy describes not the existence way and state of the general mass and energy, but the way and state of the fabric, matching and distribution of these mass and energy. The Boltzmann entropy provides a scientific basis for the generalization of the entropy concept and the entropy theory. Beside the extension of the entropy theory made by Boltzman, Schrodinger, the Austrian physicist and the quantum mechanics founder, had also put forward the "negative entropy" concept. And he regarded the increasing of the negative entropy as the symbol of the things advanced to a new state of orderliness that means evolutionary. The establishment of the negative theory fills the unbridgeable gap between the Darwin's biological evolutionism theory and the Clausius' theory, and is also a milestone in the development history of the entropy theory. In addition, Shannon, the American mathematician 
and the information theory founder, introduced the entropy theory into the information theory, and thereby established the foundation of the information theory. According to the Shannon's information entropy theory, the information entropy is defined as $S=-k \sum_{i=1}^{N} p_{i} \cdot \ln \left(p_{i}\right)$. The emergence of the information entropy greatly expanded the meaning of entropy and laid the foundation for further generalization of the concept of entropy. Moreover, other academic sectors, such as cybernetics, probability theory, number theory, astrophysics, life sciences and so on, also have done some research on the entropy theory and its variants and gain plentiful achievements respectively. For further details, you are advised to refer to Arieh [38].

\subsection{Balanced scorecard}

The balanced scorecard (BSC) method is constructed in the process of helping ADI to implement $\mathrm{ABC}$ method by Kaplan and developed by collaborative research with NolanNorton later. The traditional BSC is a kind of performance management system, which decomposes the organization's strategies into operational metrics and targets from four aspects such as financial, customer, internal business processes, and learning and growth. The BSC method serves as a strategic management tool to strengthen the implementation of the enterprise strategy. Enterprises can understand their own development situation more completely through this method. The BSC method changes the defect of the evaluation system that enterprises only pay attention to financial indexes, and achieves the balance between the enterprises' financial indexes and the non-financial indexes, the balance between the enterprises' long-term goals and the short-term goals, the balance between the enterprises' outcome indexes and the motivation indexes, the balance between the organizations' internal group and the external group, the balance between the enterprises' leading indexes and the lagging indexes. The philosophies of comprehensive and balance are considered in the BSC method and the organizational visions and strategies are converted to four concrete operation targets. The four aspects identified by BSC are interrelated. For more information please refers to articles [39-42].

Because the BSC method has the advantages of overcoming the short-term effects of the financial evaluation methods, transforming the strategies of the organization into the performance indexes and actions of each layer, helping staffs to communicate and comprehend the organization objectives and strategies, and achieving the long-term development of the organization, etc., we choose the method to determine the index system in this paper. In sub-section 4.2, we will briefly discuss the content of the four aspects determined by BSC.

\subsection{Analytic network process}

Analytic network process (ANP) is the extension of analytic hierarchy process (AHP), and it primarily aims at settling the situation that the structure of the decision making problems with dependences and feedbacks [43]. The method is formally proposed by Saaty in the $4^{\text {th }}$ International Symposium held in Vancouver in 1966. The typical structure of ANP composed of two layers: one is the network layer and another is the control layer, as shown in Fig. 1.

The ANP control layer contains problem objectives and decision criteria, while decision criteria can be multi or none and only dominated by target. But being different from decision criteria, target in the control layer is required. The ANP network layer consists of the elements dominated by the control layer. And the elements in the network layer are mutually influenced and have dependencies relationships. 


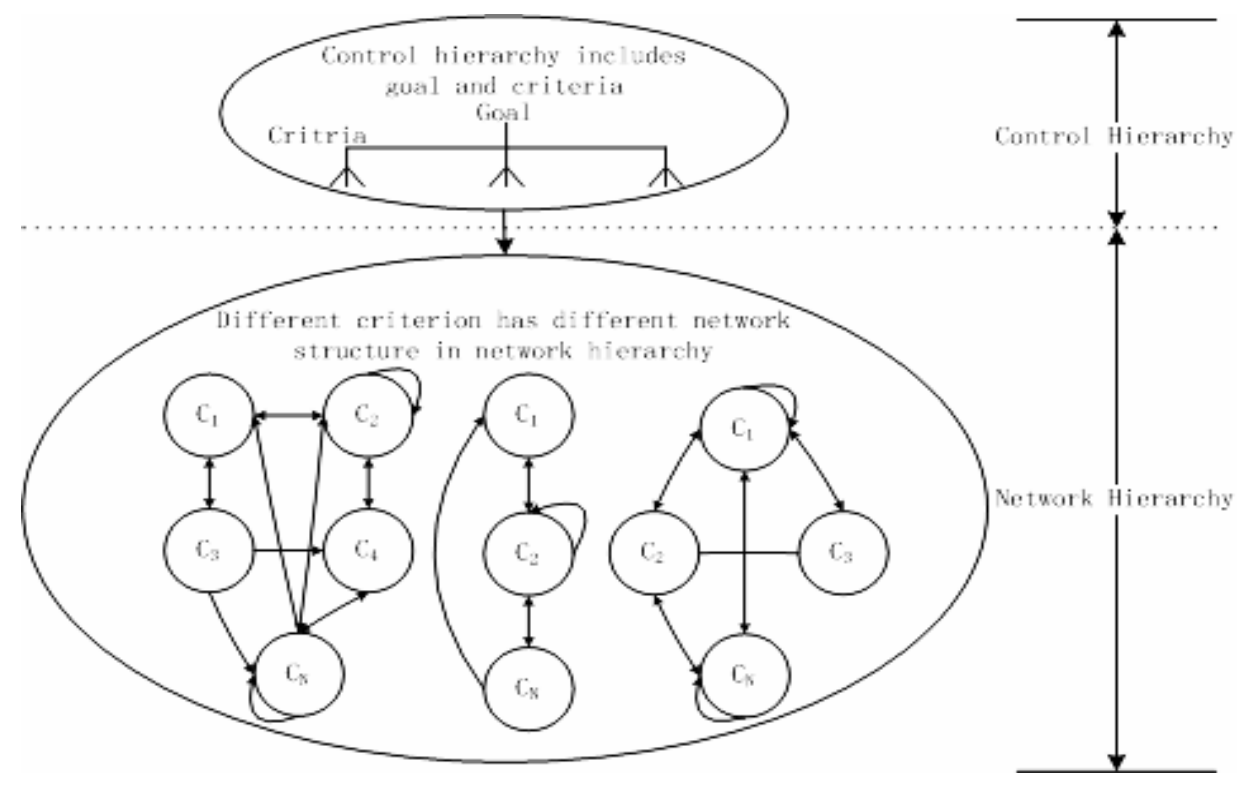

Figure 1: The structure of ANP.

In Section 3, we realize that the index weights need to be determined before state entropy calculation. And by referring to the relevant literature, there are many weight calculation methods for the index. But the indexes selected by BSC in this paper have complicated relationships. So the weight calculation method here must be able to handle these relationships. And the ANP method is in line with the requirements.

\section{DEDUCTION OF THE STATE ENTROPY}

According to the definition and expression of entropy in sub-section 2.1, we can see that entropy stands for a kind of system state in a sense. Similarly, we can consider the whole suppliers as a system and the performance of each supplier as a state of the supplier in the system. The performance of the supplier expresses at this place is the comprehensive value of every index. The optimal values of the indexes in the system are extracted to form a virtual supplier state, which we called equilibrium state. Now we assume that the performance information of every supplier in the system is accessible. So the suppliers in the system can refer the equilibrium state as a benchmark for their own development. Along with the development of the suppliers in the system, the whole system forward to balanced state and the gap between the suppliers shrinking as the state of each index of each supplier tends to optimal. There exists similarity between the evolutionary process illustrated here and the state change process in the thermodynamics. Thus we explore a mathematical method to express the performance of the supplier in the system by the concept of entropy in according to the nature of the supplier state evolutionary process. Before detailed discussion, some symbols are defined as follows.

$C$ denotes constant value;

$m$ denotes the number of the suppliers to be evaluated;

$n$ denotes the number of the criteria of the supplier evaluation;

$S_{i}$ denotes the state entropy of the $i^{\text {th }}$ supplier;

$X_{i}=\left(x_{i 1}, x_{i 2}, \ldots, x_{i n}\right)$ denotes the state vector of the $i^{\text {th }}$ supplier, $i=1,2, \ldots, m$;

$Y=\left(y_{1}, y_{2}, \ldots, y_{n}\right)$ denotes the equilibrium state vector of the supplier system;

$W=\left(w_{1}, w_{2}, \ldots, w_{n}\right)$ denotes the weight vector of the criteria;

$T_{i}=\left(t_{i 1}, t_{i 2}, \ldots, t_{i n}\right)$ denotes a mapping vector of $X_{i}, t_{i j} \in\left(u_{i j}, u_{\max }^{j}\right]$, and $u_{\text {max }}^{j}$ is the mapping value of $y_{j}, u_{i j}$ is the mapping value of $x_{i j}, i=1,2, \ldots, m, j=1,2, \ldots, n$; 
$V_{i}=\left(v_{i 1}, v_{i 2}, \ldots, v_{i n}\right)$, which $v_{i j}=\ln \left(u_{i j}\right), i=1,2, \ldots, m, j=1,2, \ldots, n$;

$\Delta \varphi_{i}$ denotes the weighted relative change amount of the state evolutionary process of the

$i^{\text {th }}$ supplier, $i=1,2, \ldots, m$;

$D_{i}=\left(d_{i 1}, d_{i 2}, \ldots, d_{i n}\right)$ denotes the distance factor between $X_{i}$ and $Y$, that is:

$D_{i}=\left|Y-X_{i}\right|^{p}=\left(\left|y_{1}-x_{i 1}\right|^{p},\left|y_{2}-x_{i 2}\right|^{p}, \ldots,\left|y_{n}-x_{i n}\right|^{p}\right), i=1,2, \ldots, m$;

$Z=\left(z_{1}, z_{2}, \ldots, z_{n}\right)$ denotes the vector formed by the maximum distance factor of each criterion of the suppliers to be evaluated, that is:

$Z=\max D_{i}=\left(\max \left|y_{1}-x_{i 1}\right|^{p}, \max \left|y_{2}-x_{i 2}\right|^{p}, \ldots, \max \left|y_{n}-x_{i n}\right|^{p}\right), i=1,2, \ldots, m$.

By the observation in real-world, the value of the index is always presented as a single crisp value. Thus it brings about a cognitive illusion that people considered the index variables is a series of discrete variables. But through in-depth observation and analysis, we can find that the change of the indexes is a continuous process and a step-by-step process. If using mathematical expression, this process can be represented as a continuous function that constrained by multiple independent variables such as $G=F(Q)$, where $Q$ is a vector formed by independent variables. Therefore, the index variables are continuous variables, and the value obtained in the real-world is just the value of a certain point of the continuous index variable. Meanwhile, the state of the supplier is a function of a series of the continuous index variables. So the state of the supplier is also a continuous variable. By the symbols defined above, we know that the mapping of $x_{i j}$, which is the current value of the $j^{\text {th }}$ index of the $i^{\text {th }}$ supplier, is $t_{i j}$. So the differential of $t_{i j}$ can be denoted by $\Delta t_{i j}$. Then the relative value is $\Delta t_{i j} / t_{i j}$. So the weighted relative variation in the state evolutionary process of the supplier is:

$$
\Delta \varphi_{i}=\sum_{j=1}^{n} w_{j} \cdot \frac{\Delta t_{i j}}{t_{i j}}
$$

To calculate definite integral for both sides of the eq. (3), we obtain:

$$
\int d \varphi_{i}=\int \sum_{j=1}^{n} w_{j} \cdot \frac{d t_{i j}}{t_{i j}}=\sum_{j=1}^{n} w_{j} \cdot \int_{u_{i j}}^{u_{\max }^{j}} \frac{d t_{i j}}{t_{i j}}=\left.\sum_{j=1}^{n} w_{j} \cdot \ln \left(t_{i j}\right)\right|_{u_{i j}} ^{u_{\max }^{j}}=\sum_{j=1}^{n} w_{j} \cdot \ln \left(u_{\max }^{j}\right)-\sum_{j=1}^{n} w_{j} \cdot \ln \left(u_{i j}\right)
$$

In the same supplier system $u_{\max }^{j}$ and $w_{j}$ are identical and certain for each index, so the term $\sum_{j=1}^{n} w_{j} \cdot \ln \left(u_{\max }^{j}\right)$ in the eq. (4) is a constant, and we replace it with $C$. Then the simplified equation is:

$$
\int d \varphi_{i}=C-\sum_{j=1}^{n} w_{j} \cdot \ln \left(u_{i j}\right)
$$

Moreover, the constant value $C$ in the eq. (5) doesn't affect the comparison of the final evaluation results, and we also can let the constant $C$ equals to zero by the function construction (the explanation will be presented later). So we can ignore the term $\sum_{j=1}^{n} w_{j} \cdot \ln \left(u_{\max }^{j}\right)$ in the eq. (4). Then we define the term $-\sum_{j=1}^{n} w_{j} \cdot \ln \left(u_{i j}\right)$ as the state entropy of the $i^{\text {th }}$ supplier. So the corresponding expression can be presented as:

$$
S_{i}=-W \cdot V_{i}^{\prime}=-\sum_{j=1}^{n} w_{j} \cdot v_{i j}=-\sum_{j=1}^{n} w_{j} \cdot \ln \left(u_{i j}\right)
$$

According to the mathematical expression of the state entropy in eq. (6), we need to determine two group variables $w_{j}$ and $u_{i j}$ before calculating the supplier state entropy. How to obtain the value of $w_{j}$ will be elaborated in Section 4. Because $u_{i j}$ is the value of $t_{i j}$ in current supplier system, we need to know the mathematical expression of $t_{i j}$ before determine the value of $u_{i j}$. By the symbols defined above, we know that the vector of the distance factor between the $i^{\text {th }}$ supplier state and equilibrium state is $D_{i}$ and the maximum vector of the 
distance factor is $Z$. So we construct $t_{i j}=\frac{1+d_{i j}}{1+z_{j}}=\frac{1+\left|y_{j}-x_{i j}\right|^{p}}{1+z_{j}}$, thus $t_{i j} \leq 1$ and is positive. By the expression of $t_{i j}$, we obtain $u_{\text {max }}^{j}=1$. Then the term $\sum_{j=1}^{n} w_{j} \cdot \ln \left(u_{\max }^{j}\right)$ in eq. (4) is equal to 0 now.

So the state entropy expression in eq. (6) which ignore the constant term in eq. (4) is feasible. Then we can obtain the value of $u_{i j}$ by the expression of $t_{i j}$ and $x_{i j}$. Meanwhile, we assume $p=1$. So the supplier state entropy can be expressed by eq. (7):

$$
S_{i}=-W \cdot V_{i}^{\prime}=-\sum_{j=1}^{n} w_{j} \cdot v_{i j}=-\sum_{j=1}^{n} w_{j} \cdot \ln \left(u_{i j}\right)=-\sum_{j=1}^{n} w_{j} \cdot \ln \left(\frac{1+d_{i j}}{1+z_{j}}\right)=-\sum_{j=1}^{n} w_{j} \cdot \ln \left(\frac{1+\left|y_{j}-x_{i j}\right|}{1+z_{j}}\right)
$$

and the corresponding state entropy of the equilibrium state is:

$$
S_{\mathrm{Y}}=-\sum_{j=1}^{n} w_{j} \cdot \ln \left(\frac{1}{1+z_{j}}\right)
$$

The following conclusions can be gained on the basis of analysis of the state entropy expression illustrated above.

1) The state entropy calculates the discrepancies between the supplier and the equilibrium state (or the optimum state) in the current supplier system. In another way, this discrepancy is the efforts that supplier need to pay to achieve the optimum state in the system.

2) The greater value of the supplier state entropy means more approaching to the equilibrium state, that is, the comprehensive evaluation of the supplier is better. Conversely, the smaller value the state entropy of the supplier has, the worse the comprehensive performance.

3) The state entropy of the equilibrium state is less than and not equal to 1 , and if the supplier state entropy need to be mapped to interval $[0,1]$, the calculation of $S_{i} / S_{Y}$ will do.

Based on the deduction process, we can summarize the calculation steps of the state entropy as follows:

Step 1: determine the weight vector $W$ of the indexes selected to evaluate the performance of the suppliers;

Step 2: collect the state information $x_{i j}$ of each index of each supplier;

Step 3: extract the optimal value of each index to form a virtual state, i.e. the equilibrium state $Y$;

Step 4: calculate the discrepancy $D_{i}$ between the supplier state and equilibrium state, and obtain the largest value of each index to form the vector $Z$;

Step 5: construct a function for $t_{i j}$ and calculate the mapping value, the function constructed in this paper is $t_{i j}=\frac{1+\left|y_{j}-x_{i j}\right|}{1+z_{j}}$;

Step 6: calculate the state entropy by the weights obtained in Step 1 and the data got from Step 5;

Step 7: do some analyses and comparisons by using the results. Compare the values obtained from Step 6 and draw the final ranking results. The analysis is mainly for the validity of the results, so that the results to be more reasonable and more conducive to the explanation and understanding for the decision-makers. At the same time, the results are adjusted when necessary.

\section{AN APPLICATION}

In previous section, we described the state entropy and deduced the formula by imitating the supplier evolutionary process. In order to verify the rationality and effectiveness of the 
method, the proposed method will be applied to an MRO enterprise in this section. First of all, the characteristics and problems of the MRO industry are analysed and summarized for the sake of obtaining the reasonable weights required in the step 1 of the state entropy calculation. Then, we select indexes from four aspects by BSC and calculate the weights by ANP. Finally, the calculation of the state entropy is carried out, and we also give some analyses of the results in the end.

\subsection{Characteristics of the large complex equipment MRO enterprises}

Maintenance, Repair and Overhaul/Operation (MRO) is the general term for the needs of various service activities in the operational process of large equipment. It is an area springing up with the process of the advanced manufacturing industry centralized in manufacturing once shift to innovation and service. Since the concept of MRO proposed just last few years in China, the corresponding research is still in the infancy stage. But for its important role in the national economic development, the research of MRO is placed as one of key projects of the National 863 Program in the period of "Eleventh Five-Year" and "Twelfth Five-Year". Currently, the activities of the large complex equipment MRO enterprises are mainly based on experiences.

\subsection{Establishment of the index system}

\subsubsection{Confirmation of the indexes}

This sub-section briefly introduces the index determination based on the preference and characteristics of the MRO enterprise by BSC.

i) Financial

The financial situation plays very important role in the evaluation of the enterprise, and the financial indexes can reflect the economic capabilities and risk resistance capacity of the enterprise. Because there are many financial indexes, the index selection should be screened carefully to meet the requirement of the enterprise. First of all, the selected supplier must have sufficient funds to guarantee the daily operations and provide appropriate service. This is the most basic requirement. Secondly, the profitability is also important to the supplier for longterm cooperation. Thirdly, the supplier also needs emergency response ability to cope with unexpected events, i.e. has certain capability of business security, which is determined by the uncertainty characteristics of the large complex equipment MRO. Through above analysis, we select quick ratio, asset-liability ratio, ROE, asset turnover and ROA as the supplier evaluation indexes for the MRO enterprise.

ii) Learning and growth of the supplier

The growth and adaptability of the supplier should be considered in the process of the supplier selection if enterprise wants to make a long-term relationship with the supplier and keep this relationship in the evolving society. So we choose employee's training opportunities of the supplier, the skill of the staffs, employee's innovation ability, employee's satisfaction, employee's retention and the development planning of the supplier.

\subsubsection{The structure of the index system}

The index system of the supplier evaluation and selection of the large complex equipment MRO enterprise can be summed up in the structure shown in Fig. 2 finally after the analysis by BSC. In order to easy identification and convenient for data inputting, the corresponding identifier is added in front of each index. 


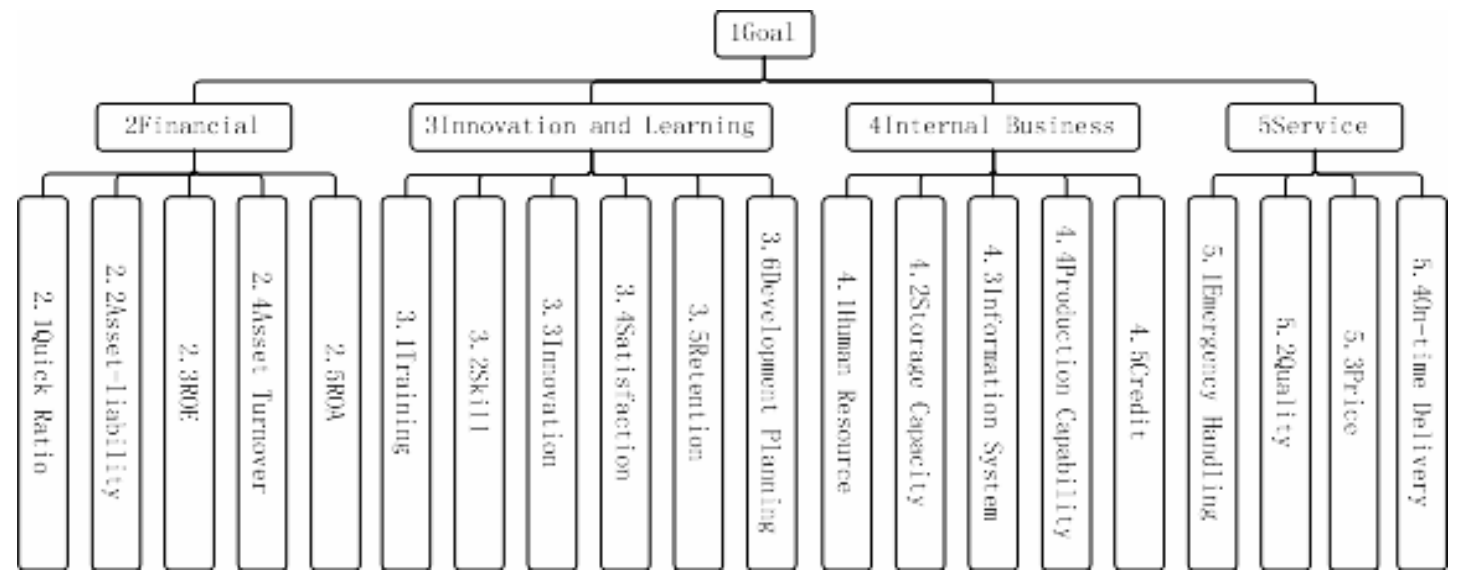

Figure 2: The index system of supplier evaluation and selection of the MRO enterprise.

The index system in Fig. 2 is divided into three levels, and it is the graphical presentation of the content of the subsection 4.2.1. Fig. 2 shows a hierarchical relationship between the indexes in the index system established in this paper. But in the real environment this hierarchical relationship is just one of the relationships between indexes. For the sake of revealing more general relationship, we consult the field experts in the MRO enterprise. The relationships between the indexes obtained ultimately are shown in Fig. 3.

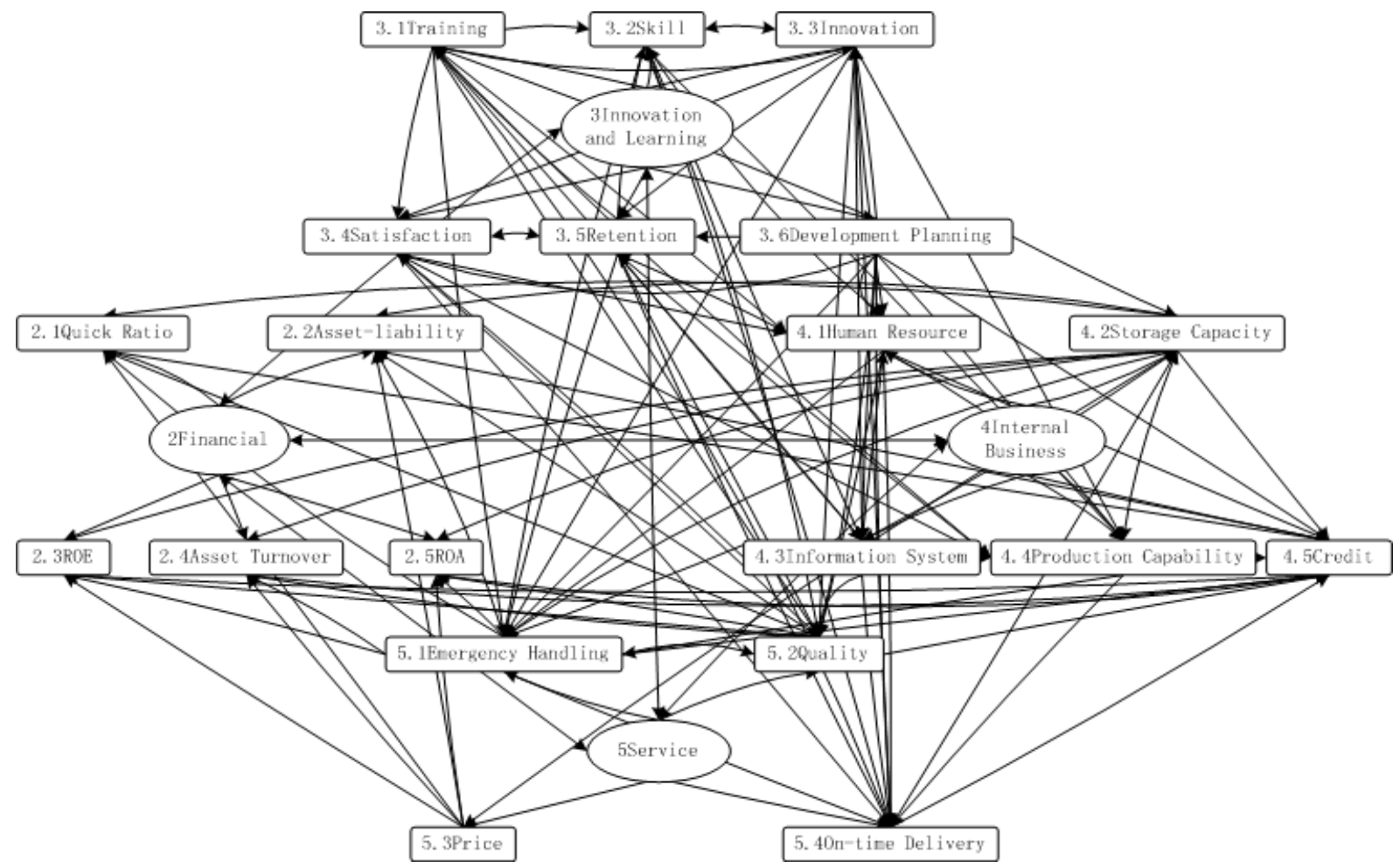

Figure 3: Inner and outer dependencies among the elements.

Fig. 3 shows the relationship between the indexes. And such relationship is very complex in real-world environment. From Fig. 3, we can clearly find that the relationship between indexes not only exist in the parent indexes and the child indexes, but also widespread in the child indexes and the child indexes, the parent indexes and the parent indexes, the child indexes and the parent indexes. And the later three relations are always ignored in many studies. 


\subsection{Weight calculations}

As the intricate relationships between the indexes, the supermatrix will be involved when using ANP method. So we refer to the software of Super Decision (SD) provided by Saaty. First of all, the relationships between indexes depicted in the Fig. 3 in the subsection 4.2.2 are input into the SD, and the output is shown in Fig. 4.

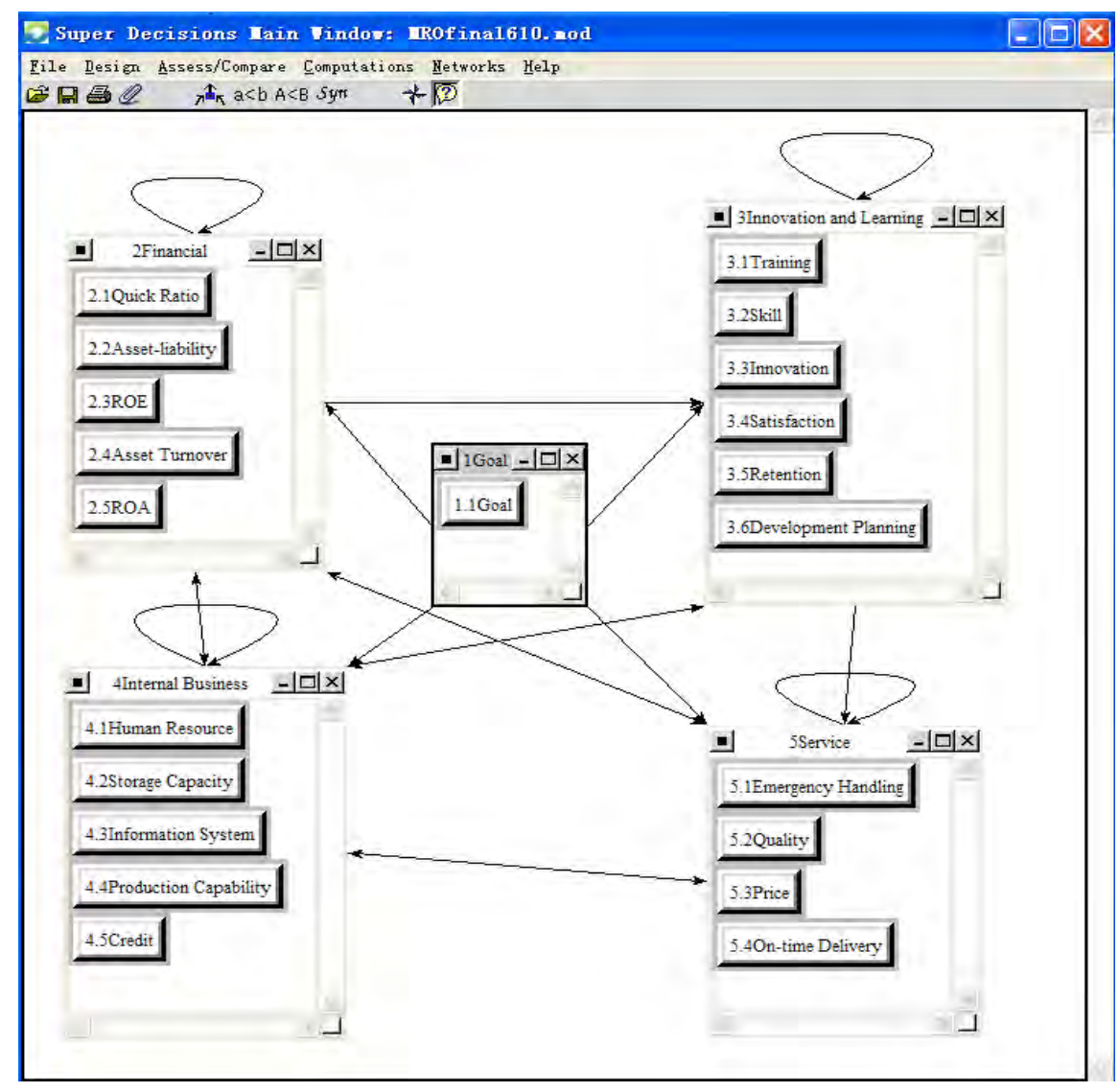

Figure 4: The relationship diagram created by SD.

Fig. 4 epitomizes the relations in Fig. 3. So the complex relationship in Fig. 3 has been simplified and more visually articulated. From Fig. 4, we can easily find that the internal dependencies and the external dependencies among the indexes. And these two dependencies make the relationship between the indexes very complicated in real-world. The ANP method can fully reflect these relationships, which makes the results calculated by ANP much more realistic and accurate.

After sorting out the relationships between indexes, we adopt pairwise comparison to quantify the relationships and then consistency tests are also employed here. The number of tables obtained shown as Table I is 62 .

Table I: Pairwise comparisons.

(a) C.R. $=0.0978$

\begin{tabular}{|c|c|c|c|c|}
\hline$[\mathbf{1}]$ & {$[2]$} & {$[3]$} & {$[\mathbf{4}]$} & {$[\mathbf{5}]$} \\
\hline$[2]$ & 1 & $1 / 3$ & $1 / 5$ & $1 / 8$ \\
\hline$[3]$ & 3 & 1 & $1 / 3$ & $1 / 5$ \\
\hline$[4]$ & 5 & 3 & 1 & $1 / 5$ \\
\hline$[5]$ & 8 & 5 & 5 & 1 \\
\hline
\end{tabular}

(b) C.R. $=0.0787$

\begin{tabular}{|c|c|c|c|c|}
\hline $\mathbf{1 . 1 - > 5}]$ & {$[\mathbf{5 . 1}]$} & $\mathbf{5 . 2}]$ & $\mathbf{5 . 3}]$ & $\mathbf{5 . 4}]$ \\
\hline$[\mathbf{5 . 1}]$ & 1 & 3 & 6 & 2 \\
\hline$[\mathbf{5 . 2}]$ & $1 / 3$ & 1 & 5 & 2 \\
\hline$[\mathbf{5 . 3}]$ & $1 / 6$ & $1 / 5$ & 1 & 5 \\
\hline$[\mathbf{5 . 4}]$ & $1 / 2$ & $1 / 2$ & $1 / 5$ & 1 \\
\hline
\end{tabular}


(c) C.R. $=0.0770$

\begin{tabular}{|c|c|c|c|}
\hline$[3.3->3]$ & {$[3.2]$} & {$[3.4]$} & {$[3.5]$} \\
\hline$[3.2]$ & 1 & 6 & 3 \\
\hline$[3.4]$ & $1 / 6$ & 1 & $1 / 2$ \\
\hline$[3.5]$ & $1 / 3$ & 2 & 1 \\
\hline
\end{tabular}

(e) C.R. $=0.0737$

\begin{tabular}{|c|c|c|c|c|c|}
\hline$[2.2->4]$ & {$[4.1]$} & {$[4.2]$} & {$[4.3]$} & {$[4.4]$} & {$[4.5]$} \\
\hline$[4.1]$ & 1 & $1 / 5$ & $1 / 2$ & $1 / 5$ & $1 / 3$ \\
\hline$[4.2]$ & 5 & 1 & 5 & 3 & 3 \\
\hline$[4.3]$ & 2 & $1 / 5$ & 1 & $1 / 3$ & $1 / 4$ \\
\hline$[4.4]$ & 5 & $1 / 3$ & 3 & 1 & $1 / 2$ \\
\hline$[4.5]$ & 3 & $1 / 3$ & 4 & 2 & 1 \\
\hline
\end{tabular}

(g) C.R. $=0.0797$

$[4.1$->3][3.1][3.2] [3.3][3.4][3.5]

\begin{tabular}{|c|c|c|c|c|c|}
\hline$[3.1]$ & 1 & $1 / 5$ & $1 / 3$ & 3 & 3 \\
\hline$[3.2]$ & 5 & 1 & 4 & 7 & 7 \\
\hline$[3.3]$ & 3 & $1 / 4$ & 1 & 5 & 5 \\
\hline$[3.4]$ & $1 / 3$ & $1 / 7$ & $1 / 5$ & 1 & 2 \\
\hline$[3.5]$ & $1 / 3$ & $1 / 7$ & $1 / 5$ & $1 / 2$ & 1 \\
\hline
\end{tabular}

(i) C.R. $=0.0820$

\begin{tabular}{|c|c|c|c|c|c|}
\hline$[\mathbf{5 . 1}->\mathbf{2}]$ & {$[\mathbf{2 . 1}]$} & {$[\mathbf{2 . 2}]$} & {$[\mathbf{2 . 3}]$} & {$[\mathbf{2 . 4}]$} & {$[\mathbf{2 . 5}$} \\
\hline$[\mathbf{2 . 1}]$ & 1 & 7 & 3 & 5 & 3 \\
\hline$[\mathbf{2 . 2}]$ & $1 / 7$ & 1 & $1 / 3$ & 2 & $1 / 3$ \\
\hline$[\mathbf{2 . 3}]$ & $1 / 3$ & 3 & 1 & 3 & 3 \\
\hline$[\mathbf{2 . 4}]$ & $1 / 5$ & $1 / 2$ & $1 / 3$ & 1 & $1 / 3$ \\
\hline$[\mathbf{2 . 5}]$ & $1 / 3$ & 3 & $1 / 3$ & 3 & 1 \\
\hline
\end{tabular}

(k) C.R. $=0.0667$

\begin{tabular}{|c|c|c|c|c|c|c|}
\hline $1->3$ & 3.1 & {$[3.2$} & .3] & {$[3.4$} & {$[3.5$} & {$[3.6$} \\
\hline [3.1] & 1 & $1 / 7$ & $1 / 3$ & $1 / 3$ & $1 / 3$ & $1 / 5$ \\
\hline [3.2] & 7 & 1 & 5 & 4 & 4 & 2 \\
\hline$[3.3]$ & 3 & $1 / 5$ & 1 & $1 / 2$ & $1 / 2$ & $1 / 5$ \\
\hline$[3.4]$ & 3 & $1 / 4$ & 2 & 1 & 1 & $1 / 5$ \\
\hline$[3.5]$ & 3 & $1 / 4$ & 2 & 1 & 1 & $1 / 5$ \\
\hline$[3.6]$ & 5 & $1 / 2$ & 5 & 5 & 5 & 1 \\
\hline
\end{tabular}

(d) C.R. $=0.0810$

\begin{tabular}{|c|c|c|c|}
\hline$[3.2->5$ & {$[5.1]$} & {$[\mathbf{5 . 2}]$} & {$[\mathbf{5 . 4}]$} \\
\hline$[\mathbf{5 . 1}]$ & 1 & $1 / 5$ & 3 \\
\hline$[\mathbf{5 . 2}]$ & 5 & 1 & 6 \\
\hline$[\mathbf{5 . 4}]$ & $1 / 3$ & $1 / 6$ & 1 \\
\hline
\end{tabular}

(f) C.R. $=0.0368$

\begin{tabular}{|c|c|c|c|c|c|}
\hline$[3.6$->4] $][4.1]$ & {$[4.2]$} & {$[4.3$} & {$[4.4]$} & {$[4.5]$} \\
\hline$[4.1]$ & 1 & 1 & $1 / 5$ & $1 / 3$ & $1 / 5$ \\
\hline$[4.2]$ & 1 & 1 & $1 / 5$ & $1 / 3$ & $1 / 5$ \\
\hline$[4.3]$ & 5 & 5 & 1 & 3 & 2 \\
\hline$[4.4]$ & 3 & 3 & $1 / 3$ & 1 & $1 / 3$ \\
\hline$[4.5]$ & 5 & 5 & 2 & 3 & 1 \\
\hline
\end{tabular}

(h) C.R. $=0.0870$

$|[4.5->2]|[2.1][2.2][2.3][2.4][2.5]$

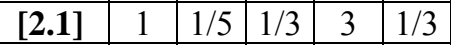

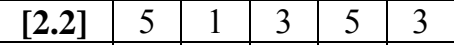

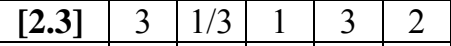

\begin{tabular}{c|c|c|c|c|c|}
{$[\mathbf{2 . 4}]$} & $1 / 3$ & $1 / 5$ & $1 / 3$ & 1 & $1 / 3$ \\
\hline$[2.5]$ & 3 & $1 / 3$ & $1 / 2$ & 3 & 1 \\
\hline
\end{tabular}

(j) C.R. $=0.0822$

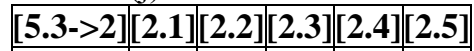

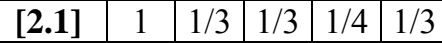

\begin{tabular}{|c|c|c|c|c|c|}
\hline [2.2] & 3 & 1 & $1 / 2$ & $1 / 3$ & $1 / 3$ \\
\hline$[2.3]$ & 3 & 2 & 1 & 2 & 2
\end{tabular}

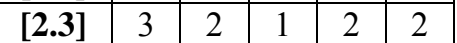

\begin{tabular}{c|c|c|c|c|c|}
\hline$[2.4]$ & 4 & 3 & $1 / 2$ & 1 & $1 / 2$ \\
\hline$[2.5]$ & 3 & 3 & $1 / 2$ & 2 & 1 \\
\hline
\end{tabular}

\begin{tabular}{l|l|l|l|l|l|}
{$[\mathbf{2 . 5}]$} & 3 & 3 & $1 / 2$ & 2 & 1 \\
\hline
\end{tabular}

(1) C.R. $=0.0298$

$[2.5->3][3.1][3.2][3.3][3.4][3.5][3.6]$

\begin{tabular}{|c|c|c|c|c|c|c|}
\hline$[3.1]$ & 1 & 1 & $1 / 5$ & 1 & 1 & $1 / 7$ \\
\hline$[3.2]$ & 1 & 1 & $1 / 5$ & 1 & 1 & $1 / 7$ \\
\hline$[3.3]$ & 5 & 5 & 1 & 5 & 5 & $1 / 3$ \\
\hline$[3.4]$ & 1 & 1 & $1 / 5$ & 1 & 1 & $1 / 7$ \\
\hline$[3.5]$ & 1 & 1 & $1 / 5$ & 1 & 1 & $1 / 7$ \\
\hline$[3.6]$ & 7 & 7 & 3 & 7 & 7 & 1 \\
\hline
\end{tabular}

4.3.1 Preliminary supermatrix

Input the obtained data in the 62 tables to SD, then we get preliminary supermatrix as shown in Table II.

Table II: Preliminary supermatrix.

\begin{tabular}{|c|c|c|c|c|c|c|c|c|c|c|c|c|c|c|c|c|c|c|c|c|c|}
\hline & \begin{tabular}{|l|}
{$[1.1]$} \\
\end{tabular} & [2.1] & $\begin{array}{l}{[2.2]} \\
\end{array}$ & [2.3] & [2.4] & [2.5] & [3.1] & [3.2] & [3.3] & [3.4] & $\begin{array}{l}3.5] \\
\end{array}$ & [3.6] & [4.1] & [4.2] & [4.3] & {$[4.4]$} & [4.5] & [5.1] & {$[5.2]$} & [5.3] & \begin{tabular}{|l|}
{$[5.4]$} \\
\end{tabular} \\
\hline$[1.1]$ & 0 & 0 & 0 & 0 & 0 & 0 & 0 & 0 & 0 & 0 & 0 & 0 & 0 & 0 & 0 & 0 & 0 & 0 & 0 & 0 & 0 \\
\hline 22.1$]$ & 0.1273 & 0 & 0.6987 & 0.1267 & 0.1138 & 0.0492 & 0 & 0 & 0 & 0 & 0 & 0 & 0 & 0.1630 & 0 & 0 & 0.0937 & 0.4714 & 0.2 & 0.0676 & 0 \\
\hline$[2.2]$ & 0.0748 & \begin{tabular}{|l|}
0.5950 \\
\end{tabular} & 0 & 0.0399 & \begin{tabular}{|l|}
0.0374 \\
\end{tabular} & 0.5950 & 0 & 0 & 0 & 0 & 0 & 0 & 0 & \begin{tabular}{|l|}
0.0602 \\
\end{tabular} & 0 & 0 & 0.4551 & \begin{tabular}{|l|}
0.0753 \\
\end{tabular} & \begin{tabular}{|l|}
0.2 \\
\end{tabular} & 0.1218 & 0 \\
\hline$[2.3]$ & 0.3545 & \begin{tabular}{|l|}
0.2487 \\
\end{tabular} & 0.0847 & 0 & 0.4244 & 0.2487 & 0 & 0 & 0 & 0 & 0 & 0 & 0 & 0.3570 & 0 & 0 & 0.2226 & 0.2399 & \begin{tabular}{|l|} 
\\
\end{tabular} & 0.3266 & 0 \\
\hline [2.4] & 0.0808 & 0.1071 & 0.1320 & 0.2674 & T. & 0.1071 & 0 & 0 & 0 & 0 & 0 & 0 & 0 & 0.0629 & 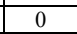 & 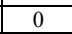 & 0.0593 & 0.0616 & \begin{tabular}{|l|}
0.2 \\
\end{tabular} & 0.2155 & 0 \\
\hline$[2.5]$ & 0.3625 & \begin{tabular}{|l|}
0.0492 \\
\end{tabular} & 0.0847 & 0.5660 & 0.4244 & 0 & 0 & 0 & 0 & 0 & 0 & 0 & 0 & 0.3570 & 0 & 0 & 0.1693 & 0.1519 & \begin{tabular}{|l|}
0.2 \\
\end{tabular} & 0.2685 & 0 \\
\hline [3.1] & 0.0389 & \begin{tabular}{|l|}
0.0809 \\
\end{tabular} & 0.0672 & 0.0704 & 0.0600 & 0.0600 & 0 & 0 & 0 & 0 & 0 & 0.0669 & 0.1183 & 0 & 0.1135 & 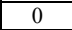 & 0 & 0 & $\overline{0}$ & 0 & 0 \\
\hline [3.2] & 0.3825 & 0.0809 & 0.0672 & 0.0704 & 0.0600 & 0.0600 & 0.2338 & 0 & 0.6667 & 0 & 0.1667 & 0 & 0.5372 & 0 & 0.2520 & 0 & 0 & 0 & 0 & 0 & 0 \\
\hline [3.3] & 0.0670 & \begin{tabular}{|l|}
0.2227 \\
\end{tabular} & 0.1810 & 0.2030 & 0.2691 & 0.2691 & 0.5260 & 1 & 0 & 0 & 0 & 0.6138 & 0.2390 & 0 & 0.5413 & 0 & 0 & 0 & 0 & 0 & 0 \\
\hline$[3.4]$ & 0.0961 & 0.0809 & 0.0672 & 0.0704 & 0.0600 & 0.0600 & 0.0829 & 0 & 0.1111 & 0 & 0.8333 & 0.2073 & 0.0599 & 0 & 0.0364 & 0 & 0 & 0 & 0 & 0 & 0 \\
\hline$[3.5]$ & 0.0961 & \begin{tabular}{|l|}
0.0809 \\
\end{tabular} & 0.0672 & 0.0704 & 0.0600 & 0.0600 & \begin{tabular}{|l|l|} 
\\
\end{tabular} & 0 & 0.2222 & 1 & 0 & 0.1120 & 0.0456 & 0 & \begin{tabular}{|l|}
0.0567 \\
\end{tabular} & 0 & 0 & 0 & 0 & 0 & 0 \\
\hline$[3.6]$ & 0.3193 & \begin{tabular}{|l|}
0.4537 \\
\end{tabular} & 0.5501 & 0.5153 & 0.4909 & 0.4909 & 0 & 0 & 0 & 0 & 0 & 0 & 0 & 0 & 0 & 0 & 0 & 0 & 0 & 0 & 0 \\
\hline [4.1] & 0.0342 & 0.0520 & 0.0557 & 0.0480 & 0.0457 & \begin{tabular}{|l|}
0.0478 \\
\end{tabular} & 0.2684 & 0.7306 & 0.6370 & \begin{tabular}{|l|}
0.8333 \\
\end{tabular} & 0.6370 & 0.0626 & 0 & 0 & 0.7306 & 0 & 0 & 0 & 0 & 0 & 0 \\
\hline [4.2] & 0.2748 & \begin{tabular}{|l|}
0.3849 \\
\end{tabular} & 0.4517 & 0.0833 & 0.4251 & 0.1015 & 0 & 0 & 0 & 0 & 0 & 0.0626 & 0 & 0 & 0.0810 & 0.2500 & 0 & 0 & 0 & 0 & 0.1250 \\
\hline [4.3] & 0.1122 & 0.1121 & 0.0770 & 0.1494 & 0.1390 & 0.2613 & 0.6144 & 0.1884 & 0.2583 & 0 & 0.2583 & 0.3117 & 0.6483 & 0 & 0 & 0 & 0 & 0 & 0 & 0 & 0 \\
\hline [4.4] & 0.1122 & \begin{tabular}{|l|}
0.1935 \\
\end{tabular} & 0.2394 & 0.3116 & 0.1256 & 0.0973 & 0.1172 & 0.0810 & 0.1047 & 0.1667 & 0.1047 & 0.1500 & 0.1220 & 0.8333 & 0.1884 & 0 & 0 & 0 & 0 & 0 & 0 \\
\hline$[4.5]$ & 0.4665 & 0.2574 & 0.1762 & 0.4076 & 0.2646 & 0.4920 & 0 & 0 & 0 & 0 & 0 & 0.4131 & 0.2297 & 0.1667 & 0 & 0.7500 & 0 & 1 & 1 & 0 & 0.8750 \\
\hline [5.1] & 0.4793 & 0.1047 & 0.1634 & 0.0810 & 0.0811 & \begin{tabular}{|l|}
0.0953 \\
\end{tabular} & \begin{tabular}{|l|l|}
0.1884 \\
\end{tabular} & 0.1947 & 0.1721 & 0 & 0.1007 & 0.0914 & 0.1047 & 0.1429 & 0.1884 & 0.1667 & 0 & 0 & 0 & 0 & 0 \\
\hline [5.2] & 0.2636 & \begin{tabular}{|l|}
0.6370 \\
\end{tabular} & 0.5396 & 0.7306 & 0.5769 & 0.6548 & 0.7306 & 0.7172 & 0.7258 & 0.1667 & 0.6738 & 0.6910 & 0.6370 & 0 & 0.7306 & 0 & 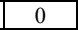 & 0.1667 & 0 & 0 & 0 \\
\hline [5.3] & 0.0545 & 0 & 0 & 0 & 0 & 0 & 0 & 0 & 0 & 0 & 0 & 0 & 0 & 0.7143 & 0 & 0 & 0 & 0 & 0 & 0 & 0 \\
\hline [5.4] & 0.2026 & \begin{tabular}{|l|}
0.2583 \\
\end{tabular} & 0.2970 & 0.1884 & 0.3420 & 0.2499 & 0.0810 & 0.0881 & 0.1020 & \begin{tabular}{|l|}
0.8333 \\
\end{tabular} & 0.2255 & 0.2176 & 0.2583 & \begin{tabular}{|l|l|l|} 
\\
\end{tabular} & 0.0810 & 0.8333 & 0 & \begin{tabular}{|l|l|} 
\\
\end{tabular} & 0 & 0 & 0 \\
\hline
\end{tabular}




\subsubsection{Calculate weighted supermatrix}

By calculation rules of the weighted supermatrix in the SD, we can obtain the weighted supermatrix shown in Table III.

Table III: Weighted supermatrix.

\begin{tabular}{|c|c|c|c|c|c|c|c|c|c|c|c|c|c|c|c|c|c|c|c|c|c|}
\hline & [1.1] & {$[2.1]$} & {$[2.2]$} & {$[2.3]$} & \begin{tabular}{|l|l|}
{$[2.4]$} \\
\end{tabular} & {$[2.5]$} & [3.1] & {$[3.2]$} & {$[3.3]$} & {$[3.4]$} & [3.5] & \begin{tabular}{|l|}
$3.6]$ \\
\end{tabular} & [4.1] & {$[4.2]$} & {$[4.3]$} & {$[4.4]$} & {$[4.5]$} & \begin{tabular}{|l|l}
{$[5.1]$} \\
\end{tabular} & \begin{tabular}{|l}
{$[5.2]$} \\
\end{tabular} & [5.3] & {$[5.4]$} \\
\hline$[1.1]$ & 0 & 0 & 0 & 0 & 0 & 0 & 0 & $\overline{0}$ & 0 & 0 & 0 & 0 & 0 & 0 & 0 & 0 & 0 & 0 & 0 & 0 & \\
\hline$[2.1]$ & .0063 & 0 & 0.0735 & 0.0133 & 0.0120 & 0.0052 & 0 & 0 & 0 & 0 & 0 & 0 & 0 & 0.0284 & 0 & 0 & 0.0937 & 0.0276 & 0.0347 & 0.0676 & 0 \\
\hline$[2.2]$ & 0037 & 0.0626 & ( & 0.0042 & 0.0039 & 0.0626 & 0 & 0 & 0 & 0 & 0 & 0 & 0 & 0.0105 & 0 & I & 0.4551 & 0.0044 & 0.0347 & \begin{tabular}{|l|}
0.1218 \\
\end{tabular} & 0 \\
\hline$[2.3]$ & 174 & \begin{tabular}{|l|}
0.0262 \\
\end{tabular} & \begin{tabular}{|l|l|}
0.0089 \\
\end{tabular} & 0 & \begin{tabular}{|l|}
0.0447 \\
\end{tabular} & 0.0262 & 0 & 0 & 0 & & 0 & 0 & 0 & 0.0622 & c & & 2226 & 0.0140 & \begin{tabular}{|l|}
0.0347 \\
\end{tabular} & 0.3266 & 0 \\
\hline$[2.4]$ & 0040 & 0.0113 & \begin{tabular}{|l|l|}
0.0139 \\
\end{tabular} & \begin{tabular}{|l|}
0.0281 \\
\end{tabular} & 0 & 0.0113 & 0 & & & & & 0 & & 0.0110 & & & 0.0593 & 0.0036 & 0.0347 & 0.2155 & 0 \\
\hline$[2.5]$ & 178 & 0.0052 & 0.0089 & 0.0596 & 0.0447 & 0 & 0 & $\overline{0}$ & $\overline{0}$ & & & 0 & \begin{tabular}{ll|}
0 \\
\end{tabular} & 0.0622 & 0 & & 1.1693 & 0.0089 & $0.0347 \mid$ & 0.2685 & 0 \\
\hline$[3.1]$ & 042 & 0.0044 & \begin{tabular}{|l|l|}
0.0037 \\
\end{tabular} & \begin{tabular}{|l}
0.0039 \\
\end{tabular} & 0.0033 & 0.0033 & 0 & 0 & \begin{tabular}{|l|l|}
0 \\
\end{tabular} & & 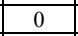 & 0.0429 & \begin{tabular}{|l|l|}
0.0063 \\
\end{tabular} & 2 & 0.0060 & & & 0 & 0 & $\Omega$ & \\
\hline [3.0.1] & 0411 & \begin{tabular}{|l|}
0.0044 \\
\end{tabular} & \begin{tabular}{|l|}
0.0037 \\
\end{tabular} & \begin{tabular}{|l|}
0.0039 \\
\end{tabular} & \begin{tabular}{|l|l|}
0.0033 \\
\end{tabular} & 0.0033 & 0.1498 & 0 & \begin{tabular}{|l|l}
0.4271 \\
\end{tabular} & 0 & $\mid 0.1068$ & 0 & \begin{tabular}{|l|}
0.0285 \\
\end{tabular} & 0 & 0.0134 & & & 0 & 0 & 0 & 0 \\
\hline$[3.3]$ & 0072 & 0.0122 & \begin{tabular}{|l|l}
0.0099 \\
\end{tabular} & 0.0112 & 0.0148 & 0.0148 & 0.3370 & 0.6406 & 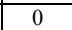 & 0 & 0 & 0.3932 & 0.0127 & 0 & 0.02 & & & 0 & 0 & 0 & 0 \\
\hline$[3.4]$ & 0.0103 & \begin{tabular}{|l|}
0.0044 \\
\end{tabular} & \begin{tabular}{|l}
0.0037 \\
\end{tabular} & \begin{tabular}{|l|l}
0.0039 \\
\end{tabular} & 0.0033 & 0.0033 & 0.0531 & 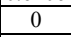 & \begin{tabular}{|l|l|}
0.0712 \\
\end{tabular} & & 0.5339 & \begin{tabular}{|l|l|}
0.1328 \\
\end{tabular} & 0.0032 & 0 & 0.00 & & & & 0 & 0 & 0 \\
\hline$[3.5]$ & 0.0103 & \begin{tabular}{|l|}
0.0044 \\
\end{tabular} & \begin{tabular}{|l|}
0.0037 \\
\end{tabular} & \begin{tabular}{|l|}
0.0039 \\
\end{tabular} & \begin{tabular}{|l|}
0.0033 \\
\end{tabular} & 0.0033 & 0.1008 & 0 & \begin{tabular}{|l|}
0.1424 \\
\end{tabular} & 0.6406 & | & \begin{tabular}{|l|l|}
0.0718 \\
\end{tabular} & \begin{tabular}{|l|}
0.0024 \\
\end{tabular} & 0 & 0.0030 & & & & 0 & 0 & 0 \\
\hline$[3.6]$ & 0343 & 0.0249 & 0.0302 & 0.0283 & 0.0270 & 0.0270 & 0 & 0 & 0 & 0 & 0 & 0 & 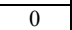 & 0 & 0 & & & 0 & 0 & 0 & 0 \\
\hline$[4.1]$ & 0074 & 0.0107 & 0.0114 & \begin{tabular}{|l|l|} 
\\
\end{tabular} & 0.0094 & 0.0098 & 0.0785 & 0.2138 & 0.1864 & 0.2438 & 0.1864 & 0.0183 & 0 & 0 & 0.2873 & & & & 0 & 0 & 0 \\
\hline$[4.2]$ & 5594 & 0.0791 & 0.0929 & \begin{tabular}{|l|l} 
\\
0.0171
\end{tabular} & 0.0874 & 0.0209 & 0 & 0 & 0 & & 0 & 0.0183 & 0 & 0 & 0.0318 & 103 & & & 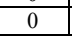 & 0 & .12 \\
\hline$[4.3]$ & 2243 & \begin{tabular}{|c|}
0.0231 \\
\end{tabular} & \begin{tabular}{|l|l|}
0.0158 \\
\end{tabular} & \begin{tabular}{|c|} 
\\
\end{tabular} & 0.0286 & 0.0537 & \begin{tabular}{|l}
0.1798 \\
\end{tabular} & \begin{tabular}{|l|}
0.0551 \\
\end{tabular} & 0.0756 & 0 & 0.0756 & 0.0912 & \begin{tabular}{|l|}
0.2549 \\
\end{tabular} & 0 & 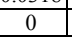 & 100 & & 0 & 0 & 0 & 12 \\
\hline$[4.4]$ & 0243 & 0.0398 & 0.0492 & 0.0641 & 0.0258 & 0.0200 & 0.0343 & \begin{tabular}{|l|l}
0.0237 \\
\end{tabular} & 0.0306 & 0.0488 & 0.0306 & 0.0439 & 0.0 & 0.28 & 0.0741 & 0 & & 0 & 0 & 0 & 0 \\
\hline$[4.5]$ & 1009 & 529 & 0.0362 & 0.0838 & 0.0544 & 0.1011 & 0 & 0 & 0 & 0 & 0 & 0.1208 & 0.0903 & 0.0571 & 0 & 0.3114 & & 0.2784 & 18264 & 0 & .87 \\
\hline$[5.1]$ & 006 & & & & & 0.0605 & 0.012 & 0.013 & & & & 0.0061 & 0.0580 & 0.0690 & & 0.0975 & & 0 & 0 & 0 & . \\
\hline$[5.2]$ & 653 & \begin{tabular}{|l|}
0.4040 \\
\end{tabular} & 0.3423 & 0.4634 & \begin{tabular}{|l|}
0.3659 \\
\end{tabular} & 0.4153 & 0.0488 & \begin{tabular}{|l|}
0.0479 \\
\end{tabular} & \begin{tabular}{|l|l|l|} 
\\
\end{tabular} & 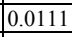 & \begin{tabular}{|l|l|}
0.0450 \\
\end{tabular} & \begin{tabular}{|l|}
0.0462 \\
\end{tabular} & \begin{tabular}{|l|}
0.3527 \\
\end{tabular} & 0 & 0.4046 & 0 & 0 & 0.1105 & 0 & 0 & 0 \\
\hline$[5.3]$ & 0.0342 & 0 & 0 & 0 & 0 & 0 & 0 & 0 & 0 & 0 & 0 & 0 & 0 & 0.3449 & 0 & & & 0 & 0 & 0 & 0 \\
\hline$[5.4]$ & 0.1271 & 163 & & & & - & 0.005 & 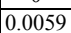 & & & 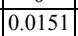 & 0 & 142 & 0.0690 & & $\overline{0.48}$ & & .552 & 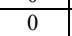 & 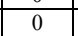 & 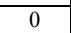 \\
\hline
\end{tabular}

\subsubsection{Calculate limit supermatrix}

The limit supermatrix shown in Table IV obtained based on the weighted supermatrix and the calculation rules of the limit supermatrix.

Table IV: Limit supermatrix.

\begin{tabular}{|c|c|c|c|c|c|c|c|c|c|c|c|c|c|c|c|c|c|c|c|c|c|}
\hline & & {$[2.1]$} & {$[2.2]$} & {$[2.3]$} & & & & {$[3.2]$} & {$[3.3]$} & {$[3.4]$} & {$[3.5]$} & {$[3.6]$} & 1] & $4.2]$ & 4.3] & [4.4] & [4.5] & [5.1] & [5.2] & {$[5.3]$} & {$[5.4]$} \\
\hline$[1.1]$ & 0 & 0 & 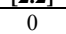 & 0 & 0 & 0 & 0 & 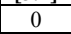 & - & 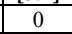 & 0 & 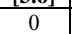 & 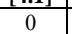 & - & 0 & 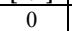 & 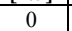 & 0 & 0 & 0 & \\
\hline$[2.1]$ & 0413 & .0413 & 041 & 0413 & 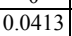 & \begin{tabular}{|c|c|}
0.0413 \\
\end{tabular} & .0413 & 0.0413 & .0413 & 041 & .041 & 0.0413 & .0413 & 0.0413 & 0.0413 & 41. & 413 & 0413 & 0413 & 3413 & \\
\hline$[2.2]$ & 1244 & 0.1244 & 0.1244 & 0.1244 & 0.1244 & 0.1244 & 0.1244 & 0.1244 & 0.1244 & 0.1244 & 1244 & 0.1244 & 0.1244 & 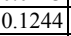 & & & & & .1244 & & \\
\hline$[2.3]$ & & & & & & & & & & & & & & & & & & & & & \\
\hline$[2.4]$ & 0274 & \begin{tabular}{|l|}
0.0274 \\
\end{tabular} & 0.0274 & 0.0274 & \begin{tabular}{|l|}
0.0274 \\
\end{tabular} & \begin{tabular}{|l|l|}
0.0274 \\
\end{tabular} & \begin{tabular}{|l|}
0.0274 \\
\end{tabular} & .0274 & 0.0274 & 0.0274 & 0.0274 & 0.0274 & 0.0274 & 0.0274 & 0.0274 & 74 & 0.0274 & 0.0274 & .0274 & 0274 & 027 \\
\hline$[2.5]$ & 5587 & \begin{tabular}{|l|l|}
0.0587 \\
\end{tabular} & & & 0.0587 & \begin{tabular}{|l|l|}
0.0587 \\
\end{tabular} & & 0587 & & & & & & & & & & & & & \\
\hline$[3.1]$ & 010 & & & & & & & & & & 讨 & & & & & & & & & & \\
\hline [3.1] & 0096 & \begin{tabular}{|l|}
0.0096 \\
\end{tabular} & 0.0096 & 0.0096 & 0.0096 & \begin{tabular}{|l|}
0.0096 \\
\end{tabular} & \begin{tabular}{|l|l|}
0.0096 \\
\end{tabular} & .0096 & 0.0096 & \begin{tabular}{|l|l|}
0.0096 \\
\end{tabular} & $|0.0096|$ & \begin{tabular}{|l|l|}
0.0096 \\
\end{tabular} & 0.0096 & 0.0096 & \begin{tabular}{|l|l|}
0.0096 \\
\end{tabular} & 0.0096 & 0.0096 & 0.0096 & 0.0096 & .009 & .00 \\
\hline$[3.3]$ & 0149 & 0.0149 & 0.0149 & 0.0149 & 0.0149 & 0.0149 & & 149 & & & 149 & & & & & & & & & & \\
\hline$[3.4]$ & 090 & 0.0090 & 0.0090 & 0.0090 & 0.0090 & 0.0090 & 90 & 090 & 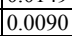 & 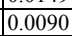 & 0090 & 090 & 0090 & 0090 & 0090 & .00 & .0090 & 09 & 009 & 0090 & \\
\hline [3.5] & 100 & \begin{tabular}{|l|}
0.0100 \\
\end{tabular} & 0.0100 & 0.0100 & 0.0100 & \begin{tabular}{|l|}
0.0100 \\
\end{tabular} & & \begin{tabular}{|l|}
0.0100 \\
\end{tabular} & 0.01 & 0.0100 & $|0.0100|$ & 0.0100 & 0.0100 & 0.0100 & 0.0100 & & & 0.0100 & 0.0100 & 0.0100 & 0 \\
\hline$[3.6]$ & 0091 & 0.0091 & 0.0091 & 0.0091 & 0.0091 & 0.0091 & \begin{tabular}{|l|}
0.0091 \\
\end{tabular} & \begin{tabular}{|l|}
0.0091 \\
\end{tabular} & \begin{tabular}{|l|}
0.0091 \\
\end{tabular} & \begin{tabular}{|l|}
0.0091 \\
\end{tabular} & 0.0091 & 0.0091 & 0.0091 & 0.0091 & 0.0091 & 0.0091 & 991 & 0091 & 0.0091 & 009 & .00 \\
\hline$[4.1]$ & 175 & .0175 & 57 & & & & & & & & & & & 201 & $\overline{01}$ & & & & & & \\
\hline $\begin{array}{l}{[7.1]} \\
{[4.2]}\end{array}$ & 1348 & \begin{tabular}{|l|}
0.0348 \\
\end{tabular} & 0.0348 & 0.0348 & \begin{tabular}{|l|l|}
0.0348 \\
\end{tabular} & \begin{tabular}{|l|l|}
0.0348 \\
\end{tabular} & \begin{tabular}{|l|l|}
0.0348 \\
\end{tabular} & 348 & 0.0 & \begin{tabular}{|l}
0.0348 \\
\end{tabular} & $0.0348 \mid$ & 0.0348 & 0.0348 & 0.0348 & 0.0348 & 0.0348 & 0.0348 & 0.0348 & 0.0348 & 0.0348 & 03 . \\
\hline$[4.3]$ & 171 & 0.0171 & 0.0171 & 171 & 0.0171 & 171 & 71 & 171 & 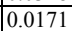 & \begin{tabular}{|l|l}
0.0171 \\
\end{tabular} & 171 & 0.0171 & 0.0171 & .0171 & 0.0171 & 0.0171 & & \begin{tabular}{|c|}
0.0171 \\
\end{tabular} & 0.0171 & 017 & \\
\hline [4.4] & 281 & & & & & & & & & & & & & & & & & & & & \\
\hline 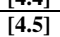 & 2434 & $\frac{202434}{.12434}$ & 0.2434 & 0.02434 & \begin{tabular}{|l|l|}
0.2434 \\
\end{tabular} & \begin{tabular}{|l|}
0.2434 \\
\end{tabular} & \begin{tabular}{|l|l|}
0.2434 \\
\end{tabular} & 0.2434 & 0.24 & \begin{tabular}{|l|}
0.2434 \\
\end{tabular} & \begin{tabular}{|l|}
0.2434 \\
\end{tabular} & \begin{tabular}{|l|l|}
0.2434 \\
\end{tabular} & 0.02434 & $\mid 0.2434$ & \begin{tabular}{|l|l|}
0.2434 \\
\end{tabular} & 0.2434 & 0.2434 & 0.2434 & \begin{tabular}{|l|l|}
0.2434 \\
\end{tabular} & \begin{tabular}{|l|l|}
0.2434 \\
\end{tabular} & $\frac{0.24}{.24}$ \\
\hline$[5.1]$ & - & & & & & & & & & & & & & & & & & & & & \\
\hline$[5.2]$ & 1454 & 0.1454 & 0.1454 & 0.1454 & 0.1454 & 0.1454 & 0.1454 & 454 & 0.1 & .1454 & $\mid 0.1454$ & 0.1454 & 0.1454 & 0.1454 & 0.1454 & 0.145 & 0.1454 & 0.1454 & 1454 & 0.1454 & \\
\hline$[5.3]$ & 1120 & .0120 & & 0120 & 0.0120 & 0.0120 & 0.0120 & $\mid \begin{array}{l}0.0120 \\
\end{array}$ & 0.01 & 0.0120 & 0.0120 & 0.0120 & 0.0120 & 0.0120 & 0.01 & 0.01 & 0.0 & 0.0120 & .0120 & .0120 & .012 \\
\hline & & & & & & & & & & & & & & & & & & & & & \\
\hline
\end{tabular}

\subsection{Results}

Now we clearly acquire the weight vector $W$ in the state entropy formula according to the steps mentioned above. And we also construct the function of $u_{i j}$ in the Section 3 . So the state entropy value of the supplier can be calculated by substituting the state vector of each supplier in the eq. (7). The supplier state information in this paper is gained from a locomotive factory, which is a factory with experience and ability for repairing variety of locomotives. The factory accounts for more than one-third of the market share of the diesel locomotive repairing work in China. As a kind of complex equipment, the structure of the locomotive is very complicated and has thousands of components and parts. In order to guarantee the locomotive repairing work be completed on time successfully, it is necessary for the locomotive factory to choose some appropriate suppliers in order to reduce all sorts of cost 
pressure. By investigation, we recognize that there are many components and parts suppliers in domestic. And we choose three of them, identified by EA, EB and EC instead of the suppliers' name, stochastically as the objects for simulation experiment in this paper. By extracting the actual operation data from the three suppliers based on the index system mentioned above and processing the data to non-dimensional data, we obtain the final data shown in Table V.

Table V: State information of the suppliers.

\begin{tabular}{|l|c|c|c|}
\hline & EA & EB & EC \\
\hline 2.1 Quick Ratio & 0.3129 & 0.4116 & 0.2755 \\
\hline 2.2 Asset-liability Ratio & 0.3333 & 0.3179 & 0.3487 \\
\hline 2.3 ROE & 0.3542 & 0.3125 & 0.3333 \\
\hline 2.4 Asset Turnover & 0.3577 & 0.3333 & 0.3089 \\
\hline 2.5 ROA & 0.3613 & 0.3109 & 0.3277 \\
\hline 3.1 Training & 0.2000 & 0.4667 & 0.3333 \\
\hline 3.2 Skill & 0.2632 & 0.4211 & 0.3158 \\
\hline 3.3 Innovation & 0.1538 & 0.3846 & 0.4615 \\
\hline 3.4 Satisfaction & 0.2667 & 0.4667 & 0.2667 \\
\hline 3.5 Retention & 0.2011 & 0.4358 & 0.3631 \\
\hline 3.6 Development Planning & 0.1765 & 0.5294 & 0.2941 \\
\hline 4.1 Human Resource & 0.2778 & 0.3889 & 0.3333 \\
\hline 4.2 Storage Capacity & 0.4286 & 0.3571 & 0.2143 \\
\hline 4.3 Information System & 0.3000 & 0.5000 & 0.2000 \\
\hline 4.4 Production Capability & 0.2778 & 0.3889 & 0.3333 \\
\hline 4.5 Credit & 0.2941 & 0.4706 & 0.2353 \\
\hline 5.1 Emergency Handling & 0.1875 & 0.5000 & 0.3125 \\
\hline 5.2 Quality & 0.2632 & 0.4211 & 0.3158 \\
\hline 5.3 Price & 0.3125 & 0.4375 & 0.2500 \\
\hline 5.4 On-time Delivery & 0.2941 & 0.4118 & 0.2941 \\
\hline
\end{tabular}

The weight vector of the indexes get by ANP in subsection 4.3.3 is: $W=(0.0413,0.1244$, $0.0707,0.0274,0.0587,0.0018,0.0096,0.0149,0.0090,0.0100,0.0091,0.0175,0.0348$, $0.0171,0.0281,0.2434,0.0326,0.1454,0.0120,0.0922)$. Then according to the state entropy calculation steps listed in the end of Section 3, we finally get $S_{E A}=0.0310, S_{E B}=0.1247$, $S_{E C}=0.0254$. Meanwhile, we also get the state entropy of the equilibrium state $S_{Z}=0.1384$. So the relative value of the state entropy of the suppliers are $S_{E A}^{*}=0.2238, S_{E B}^{*}=0.9010$, $S_{E C}^{*}=0.1834$. From the state entropy values of the three suppliers we can conclude that the supplier EB has the largest entropy, and the supplier EA is slightly larger than the supplier EC. In addition, we also can find that the comprehensive performance of supplier EB is the best among the three suppliers from daily operation. Therefore, the comprehensive performance calculated by the state entropy is in line with the actual situation.

\section{CONCLUSION}

This paper assumes that the potential suppliers of the enterprise form a system and the development of the supplier towards to the optimal value of each index in the system. Then we obtained a supplier state entropy formula by deduction based on the supplier state evolutionary process. In order to determine the variables in the formula, we designed the evaluation index system by BSC and calculated the weights of the indexes that having dependencies relationships by ANP respectively. At last, a numerical example is adopted to verify the reasonability and effectiveness of the proposed method. Although the state entropy method is applied in the supplier evaluation and selection of the MRO enterprise, it is also can 
be applied to other fields of the evaluation issues according to its deduction process and practical nature. The new proposed method in this paper is still need to be improved, and this will be a further research area. In addition, the effectiveness comparison between the new method and other evaluation methods and the integration application with other methods also need further study.

\section{REFERENCES}

[1] Verma, R.; Pullman, M. E. (1998). An analysis of the supplier selection process, Omega, Vol. 26, No. 6, 739-750, doi:10.1016/S0305-0483(98)00023-1

[2] Ng, W. L. (2008). An efficient and simple model for multiple criteria supplier selection problem, European Journal of Operational Research, Vol. 186, No. 3, 1059-1067, doi:10.1016/j.ejor.2007. $\underline{01.018}$

[3] Ho, W.; Xu, X. W.; Dey, P. K. (2010). Multi-criteria decision making approaches for supplier evaluation and selection: A literature review, European Journal of Operational Research, Vol. 202, No. 1, 16-24, doi:10.1016/j.ejor.2009.05.009

[4] Huynh, V.-N.; Nakamori, Y. (2005). Multi-expert decision-making with linguistic information: A probabilistic-based model, Proceedings of the $38^{\text {th }}$ Annual Hawaii International Conference on System Sciences, 91-100, doi:10.1109/HICSS.2005.448

[5] Bernasconi, M.; Choirat, C.; Seri, R. (2010). The analytic hierarchy process and the theory of measurement, Management Science, Vol. 56, No. 4, 699-711, doi:10.1287/mnsc.1090.1123

[6] Altuzarra, A.; Moreno-Jimenez, J. M.; Salvador, M. (2010). Consensus building in AHP-Group decision making: A Bayesian approach, Operations Research, Vol. 58, No. 6, 1755-1773, doi:10.1287/opre.1100.0856

[7] Ullah, A. M. M. S. (2005). A fuzzy decision model for conceptual design, Systems Engineering, Vol. 8, No. 4, 296-308, doi:10.1002/sys.20038

[8] Herrera, F.; Herrera-Viedma, E. (2000). Linguistic decision analysis: steps for solving decision problems under linguistic information, Fuzzy Sets and Systems, Vol. 115, No. 1, 67-82, doi:10.1016/S0165-0114(99)00024-X

[9] Herrera, F.; Herrera-Viedma, E.; Martinez, L. (2008). A fuzzy linguistic methodology to deal with unbalanced linguistic term sets, IEEE Transactions on Fuzzy Systems, Vol. 16, No. 2, 354370, doi:10.1109/TFUZZ.2007.896353

[10] Dickson, G. W. (1966). An analysis of vendor selection systems and decisions, Journal of Purchasing, Vol. 2, No. 1, 5-17

[11] Weber, C. A.; Current, J. R.; Benton, W. C. (1991). Vendor selection criteria and methods, European Journal of Operational Research, Vol. 50, No. 1, 2-18, doi:10.1016/03772217(91)90033-R

[12] Yahya, S.; Kingsman, B. (1999). Vendor rating for an entrepreneur development programme: a case study using the analytic hierarchy process method, Journal of the Operational Research Society, Vol. 50, No. 9, 916-930, doi:10.1057/palgrave.jors.2600797

[13] Yu, J.-R.; Tsai, C.-C. (2008). A decision framework for supplier rating and purchase allocation: A case in the semiconductor industry, Computers and Industrial Engineering, Vol. 55, No. 3, 634-646, doi:10.1016/j.cie.2008.02.004

[14] Ha, S. H.; Krishnan, R. (2008). A hybrid approach to supplier selection for the maintenance of a competitive supply chain, Expert Systems with Applications, Vol. 34, No. 2, 1303-1311, doi:10.1016/j.eswa.2006.12.008

[15] Chan, F. T. S.; Kumar, N. (2007). Global supplier development considering risk factors using fuzzy extended AHP-based approach, Omega, Vol. 35, No. 4, 417-431, doi:10.1016/j.omega. 2005.08.004

[16] Saen, R. F. (2010). Developing a new data envelopment analysis methodology for supplier selection in the presence of both undesirable outputs and imprecise data, International Journal of Advanced Manufacturing Technology, Vol. 51, No. 9-12, 1243-1250, doi:10.1007/s00170-010$\underline{2694-3}$ 
[17] $\mathrm{Wu}, \mathrm{D} . \mathrm{S}$. (2009). Supplier selection: A hybrid model using DEA, decision tree and neural network, Expert Systems with Applications, Vol. 36, No. 5, 9105-9112, doi:10.1016/j.eswa. 2008.12.039

[18] Saen, R. F. (2008). Supplier selection by the new AR-IDEA model, International Journal of Advanced Manufacturing Technology, Vol. 39, No. 11-12, 1061-1070, doi:10.1007/s00170-007$1287-2$

[19] Wang, J.; Lan, J. B.; Ren, P. Y.; Luo, Y. Y. (2012). Some programming models to derive priority weights from additive interval fuzzy preference relation, Knowledge-Based Systems, Vol. 27, 6977, doi:10.1016/j.knosys.2011.12.001

[20] Amid, A.; Ghodsypour, S. H.; O'Brien, C. (2006). Fuzzy multiobjective linear model for supplier selection in a supply chain, International Journal of Production Economics, Vol. 104, No. 2, 394-407, doi:10.1016/j.ijpe.2005.04.012

[21] Razmi, J.; Songhori, M. J.; Khakbaz, M. H. (2009). An integrated fuzzy group decision making/fuzzy linear programming (FGDMLP) framework for supplier evaluation and order allocation, International Journal of Advanced Manufacturing Technology, Vol. 43, No. 5-6, 590607, doi:10.1007/s00170-008-1719-7

[22] Guneri, A. F.; Yucel, A.; Ayyildiz, G. (2009). An integrated fuzzy-lp approach for a supplier selection problem in supply chain management, Expert Systems with Applications, Vol. 36, No. 5, 9223-9228, doi:10.1016/j.eswa.2008.12.021

[23] Kokangul, A.; Susuz, Z. (2009). Integrated analytical hierarch process and mathematical programming to supplier selection problem with quantity discount, Applied Mathematical Modelling, Vol. 33, No. 3, 1417-1429, doi:10.1016/j.apm.2008.01.021

[24] Razmi, J.; Rafiei, H. (2010). An integrated analytic network process with mixed-integer nonlinear programming to supplier selection and order allocation, International Journal of Advanced Manufacturing Technology, Vol. 49, No. 9-12, 1195-1208, doi:10.1007/s00170-009-2445-5

[25] Li, G.-D.; Yamaguchi, D.; Nagai, M. (2008). A grey-based rough decision-making approach to supplier selection, International Journal of Advanced Manufacturing Technology, Vol. 36, No. 910, 1032-1040, doi:10.1007/s00170-006-0910-y

[26] Che, Z. H.; Wang, H. S. (2008). Supplier selection and supply quantity allocation of common and non-common parts with multiple criteria under multiple products, Computers \& Industrial Engineering, Vol. 55, No. 1, 110-133, doi:10.1016/j.cie.2007.12.005

[27] Kubat, C.; Yuce, B. (2012). A hybrid intelligent approach for supply chain management system, Journal of Intelligent Manufacturing, Vol. 23, No. 4, 1237-1244, doi:10.1007/s10845-010-0431-2

[28] Liao, Z. Y.; Rittscher, J. (2007). Integration of supplier selection, procurement lot sizing and carrier selection under dynamic demand conditions, International Journal of Production Economics, Vol. 107, No. 2, 502-510, doi:10.1016/j.ijpe.2006.10.003

[29] Chen, K.; Xuan, Z. L.; Shang, X. L. (2009). Selection of suppliers based on BP neutral networks and grey correlation analysis, International Joint Conference on Artificial Intelligence, 268-271, doi:10.1109/JCAI.2009.52

[30] Lee, C. C.; Ou-Yang, C. (2009). A neural networks approach for forecasting the supplier's bid prices in supplier selection negotiation process, Expert Systems with Applications, Vol. 36, No. 2, 2961-2970, doi:10.1016/j.eswa.2008.01.063

[31] Wen, Y.-F. (2009). An effectiveness measurement model for knowledge management, Knowledge-Based Systems, Vol. 22, No. 5, 363-367, doi:10.1016/j.knosys.2009.02.007

[32] Yucenur, G. N.; Vayvay, O.; Demirel, N. C. (2011). Supplier selection problem in global supply chains by AHP and ANP approaches under fuzzy environment, International Journal of Advanced Manufacturing Technology, Vol. 56, No. 5-8, 823-833, doi:10.1007/s00170-011-3220-y

[33] Chamodrakas, I.; Batis, D.; Martakos, D. (2010). Supplier selection in electronic marketplaces using satisficing and fuzzy AHP, Expert Systems with Applications, Vol. 37, No. 1, 490-498, doi:10.1016/j.eswa.2009.05.043

[34] Tang, Y.-C.; Chang, C.-T. (2012). Multicriteria decision-making based on goal programming and fuzzy analytic hierarchy process: An application to capital budgeting problem, Knowledge-Based Systems, Vol. 26, 288-293, doi:10.1016/j.knosys.2011.10.005 
[35] Shemshadi, A.; Shirazi, H.; Toreihi, M.; Tarokh, M. J. (2011). A fuzzy VIKOR method for supplier selection based on entropy measure for objective weighting, Expert Systems with Applications, Vol. 38, No. 10, 12160-12167, doi:10.1016/j.eswa.2011.03.027

[36] Opricovic, S.; Tzeng, G.-H. (2004). Compromise solution by MCDM methods: A comparative analysis of VIKOR and TOPSIS, European Journal of Operational Research, Vol. 156, No. 2, 445-455, doi:10.1016/S0377-2217(03)00020-1

[37] Noor-E-Alam, M.; Lipi, T. F.; Hasin, M. A. A.; Ullah, A. M. M. S. (2011). Algorithms for fuzzy multi expert multi criteria decision making (ME-MCDM), Knowledge-Based Systems, Vol. 24, No. 3, 367-377, doi:10.1016/j.knosys.2010.10.006

[38] Arieh, B.-N. (2007). Entropy Demystified: The Second Law of Thermodynamics is Nothing But Common Sense, World Scientific Publishing Company, Singapore

[39] Wong, F. W. H.; Lam, P. T. I.; Chan, E. H. W. (2009). Optimising design objectives using the Balanced Scorecard approach, Design Studies, Vol. 30, No. 4, 369-392, doi:10.1016/j.destud. 2008.10.004

[40] Tarokh, M. J.; Shooshtari, D. F. (2005). Supply chain strategic management using transformed balanced scorecard, Proceedings of the 2005 IEEE International Engineering Management Conference, Vol. 2, 868-874, doi:10.1109/IEMC.2005.1559273

[41] Kaplan, R. S.; Norton, D. P. (1992). The balanced scorecard - measures that drive performance, Harvard Business Review, Vol. 70, No. 1, 71-79

[42] Kaplan, R. S.; Norton, D. P. (1996). Using the balanced scorecard as a strategic management system, Harvard Business Review, Vol. 74, No. 1, 75-85

[43] Saaty, T. L. (2005). Theory and Applications of the Analytic Network Process, RWS Publications, Pittsburgh 